\title{
Self-restraint and sterility in workers of Acromyrmex and Atta leafcutter ants
}

Dijkstra, Michiel Bendert; Nash, David Richard; Boomsma, Jacobus Jan

Published in:

Insectes Sociaux

DOI:

$10.1007 / \mathrm{s} 00040-004-0775-8$

Publication date:

2005

Document version

Publisher's PDF, also known as Version of record

Citation for published version (APA):

Dijkstra, M. B., Nash, D. R., \& Boomsma, J. J. (2005). Self-restraint and sterility in workers of Acromyrmex and Atta leafcutter ants. Insectes Sociaux, 52(1), 67-76. https://doi.org/10.1007/s00040-004-0775-8 


\title{
Research article
}

\section{Self-restraint and sterility in workers of Acromyrmex and Atta leafcutter ants}

\author{
M. B. Dijkstra *, D. R. Nash, J.J. Boomsma \\ Biological Institute, Department of Population Biology, Universitetsparken 15, 2100 Copenhagen, Denmark, e-mail: MDijkstra@bi.ku.dk
}

Received 1 March 2004; revised 28 June 2004; accepted 1 July 2004.

Summary. Queens of leafcutter ants (Acromyrmex and Atta) are highly multiply mated, resulting in a potential queenworker and worker-worker conflict over who should produce the males in the colony. We studied whether this conflict is expressed, by determining the amount of reproductive egglaying by workers in queenright colonies of Acromyrmex echinatior, Acromyrmex octospinosus, Atta cephalotes, and Atta sexdens through ovary dissections. Worker sons are absent or rare in queenright Acromyrmex colonies, but can be produced in orphaned colonies. In Atta, most workers have rudimentary ovaries that never produce eggs, but a few (mostly small and medium workers that form a retinue around the queen) lay many trophic eggs for consumption by the queen. These eggs are large, flaccid, and lacking in yolk compared to queen-laid eggs, and appear to be always inviable. In Acromyrmex, many workers (especially young large workers) lay eggs that are similar in size to queen-laid eggs, but mostly with a reduced amount of yolk. Trophic eggs appear to be an important source of food for larvae in Acromyrmex (especially in Ac. echinatior), but not in Atta. Five $(0.8 \%)$ of 616 dissected Ac. echinatior workers but no Ac. octospinosus workers $(\mathrm{n}=552)$, had ready-to-lay reproductive eggs. Old workers in all four species are incapable of laying eggs due to ovary resorption. We conclude that Atta workers are sterile, while Acromyrmex workers display reproductive self-restraint, possibly representing an earlier stage in the evolution towards worker sterility. Worker selfrestraint in Acromyrmex may be maintained by a queen or worker policing mechanism, but individual cost-benefit explanations may also apply.

Key words: Ovarian dissections, trophic eggs, ovary resorption, worker egg-laying, worker reproduction.

\footnotetext{
* Author for correspondence.
}

\section{Introduction}

In most eusocial Hymenoptera, workers can lay eggs but cannot mate. Because of the Hymenopteran haplodiploid sex determination system, worker-laid eggs will develop into males. Reproductive egg-laying by workers results in a potential conflict between workers and the queen over the parentage of the males. Worker egg-laying and workerderived males are common in orphaned colonies, but in queenright colonies the contribution of workers to the production of males varies greatly between species (Choe, 1988; Bourke, 1988). Of special interest is the parentage of males in species with highly multiply mated queens, e.g. honeybees, some vespine wasps (Foster and Ratnieks, 2000, 2001), leafcutter ants (Boomsma et al., 1999; Fjerdingstad et al., 1998; Fjerdingstad and Boomsma, 2000; Ortius-Lechner et al., 2003; Sumner et al., 2004), Pogonomyrmex harvester ants (Cole and Wiernasz, 1999), and army ants (Kronauer et al., in press). A high effective queen mating frequency is a sufficient condition for natural selection to favor worker policing (Ratnieks, 1988), without the need for colony-level productivity costs of worker reproduction (Ratnieks, 1988) or workers preferring a more female-biased colony investment sexratio (Foster and Ratnieks, 2001a). In species with worker policing, adult males are predicted to be mainly queenderived, although workers may still attempt to lay eggs. Worker policing through aggression towards reproductive workers or discrimination against worker-laid eggs has been demonstrated in several singly- and multiply-mated species, e.g. honeybees (Visscher and Ratnieks, 1990), Vespula wasps (Foster and Ratnieks, 2001), Dolichovespula wasps (Foster and Ratnieks, 2000); Vespa hornets (Foster and Ratnieks, 2002); and Aphaenogaster ants (Iwanishi et al., 2003).

The total fitness of a worker is the sum of her net contribution to the colony's production of virgin queens, queen sons, and sons of other workers (indirect fitness), and the number of her own sons that reach maturity and are capable of mating (direct fitness), each weighted by the relevant 
relatedness coefficient. Due to various constraints (Cole 1986), reproductive workers are predicted to do less work than non-reproductive workers, resulting in a negative correlation between direct and indirect fitness. Workers are under selection to maximize their total fitness by adjusting their investment in working and egg-laying. Under effective policing, the total fitness may be higher in non-reproductive workers than in reproductive workers because worker-laid eggs are invariably removed, while reproductive workers continue to pay the inclusive fitness price of a lower working ability. Self-restraint may thus be selectively favored as an evolutionary consequence of effective policing, and may explain the near-absence of reproductive workers in queenright honeybee colonies (Ratnieks, 1988). However, selfrestraint may also be selectively favored in the absence of policing, e.g. when worker sons mature later than queen sons and therefore have reduced mating success (Duchateau et al., 2004). Possibly as a result of self-restraint, worker egg-laying has secondarily gained a nutritive function in many ants and stingless bees. In these species, workers lay specialized trophic eggs of reduced viability that have a distinct morphology and function as food for the queen or larvae (Hölldobbler and Wilson, 1990; Crespi, 1992). In many species, workers can switch from laying trophic eggs to reproductive eggs after queen loss (Crespi, 1992).

Given the ecological importance of the leafcutter ants and the large number of evolutionary studies on this group during the last decade (for a review see e. g. Price et al., 2003), worker egg-laying in this tribe has remained understudied. The only studies available so far are by Murakami et al. (2000), who dissected small numbers of Acromyrmex octospinosus workers and reported no fully developed eggs, without giving further details, and by Bazire-Benazet (1970), who showed that some workers of Atta laevigata lay trophic eggs that they feed to the queen. In addition, genetic marker studies have so far failed to find evidence of worker reproduction in queenright colonies of the leafcutter ant Ac. octospinosus (Boomsma et al., 1999) and a number of closely related fungusgrowing ant genera (Villesen and Boomsma, 2003). The aim of the present study is to determine the frequency and within-nest distribution of trophic and reproductive egg-laying workers in queenright leafcutter ant colonies, and to unravel some of the ultimate and proximate causes of the observed patterns of self-restraint and worker sterility.

\section{Materials and methods}

We sampled workers from eight leafcutter ant colonies maintained in the laboratory, two colonies each of Acromyrmex echinatior, Acromyrmex octospinosus, Atta sexdens, and Atta cephalotes. The colonies were kept in darkness at constant $70 \% \mathrm{RH}$ and $25{ }^{\circ} \mathrm{C}$. Fungus gardens were kept under inverted plastic beakers inside plastic boxes coated with Fluon $^{\mathrm{TM}}$ (ICI Chemicals Ltd.). The colonies received fresh bramble leaves and dry rice twice weekly inside a plastic container, and fresh fruit every two weeks. All colonies had a single functional queen and had been stable in the laboratory for at least six months prior to sampling. Sexuals were produced by the two Ac. echinatior colonies only. Details of the colonies are given in Table 1.

Leafcutter ants show conspicuous worker size polymorphism, but sub-castes generally do not have discrete size ranges due to the occasional occurrence of intermediate individuals (Wetterer, 1999). In Atta, we distinguished large workers (LW, head width $>2.70 \mathrm{~mm}$ ), media workers (MW, head width $1.35-2.69 \mathrm{~mm}$ ), and small workers (SW, head width $<1.35 \mathrm{~mm}$ ). In Acromyrmex, we distinguished only large workers ( $\mathrm{LW}$, head width $>1.50 \mathrm{~mm}$ ) and small workers (SW, head width $<1.50 \mathrm{~mm}$ ). Head width was defined as the widest head width in
Table 1. Colonies used in the study. Fungus volume represents the number and size of upturned beakers containing the fungus garden. $\mathrm{LW}=$ Large workers, MW = media workers, $\mathrm{SW}=$ small workers.

\begin{tabular}{|c|c|c|c|c|}
\hline Colony & Species & Origin & $\begin{array}{l}\text { Fungus garden } \\
\text { volume }\end{array}$ & $\begin{array}{l}\text { Number of } \\
\text { dissected workers }\end{array}$ \\
\hline Ae145 & Acromyrmex echinatior & Panama & $\begin{array}{l}1 \times 1 \mathrm{~L}+ \\
1 \times 0.4 \mathrm{~L}\end{array}$ & $\begin{array}{l}190 \mathrm{LW} \\
115 \mathrm{SW}\end{array}$ \\
\hline Ae150 & Acromyrmex echinatior & Panama & $2 \times 1 \mathrm{~L}$ & $\begin{array}{l}174 \mathrm{LW} \\
137 \mathrm{SW}\end{array}$ \\
\hline Ao35 & Acromyrmex octospinosus & Panama & $2 \times 1 \mathrm{~L}$ & $\begin{array}{l}169 \mathrm{LW} \\
146 \mathrm{SW}\end{array}$ \\
\hline Ao86 & Acromyrmex octospinosus & Panama & $2 \times 1 \mathrm{~L}$ & $\begin{array}{l}102 \mathrm{LW} \\
135 \mathrm{SW}\end{array}$ \\
\hline AtcT1 & Atta cephalotes & Trinidad & $4 \times 1 \mathrm{~L}$ & $\begin{array}{l}69 \mathrm{LW} \\
156 \mathrm{MW} \\
176 \mathrm{SW}\end{array}$ \\
\hline AtcT2 & Atta cephalotes & Trinidad & $4 \times 1 \mathrm{~L}$ & $\begin{array}{l}56 \mathrm{LW} \\
124 \mathrm{MW} \\
116 \mathrm{SW}\end{array}$ \\
\hline Ats 1 & Atta sexdens & Panama & $2 \times 1 \mathrm{~L}$ & $\begin{array}{l}49 \mathrm{LW} \\
132 \mathrm{MW} \\
175 \mathrm{SW}\end{array}$ \\
\hline Ats2 & Atta sexdens & Panama & $2 \times 1 \mathrm{~L}$ & $\begin{array}{l}51 \mathrm{LW} \\
130 \mathrm{MW} \\
182 \mathrm{SW}\end{array}$ \\
\hline
\end{tabular}


Table 2. Worker behavioral categories.

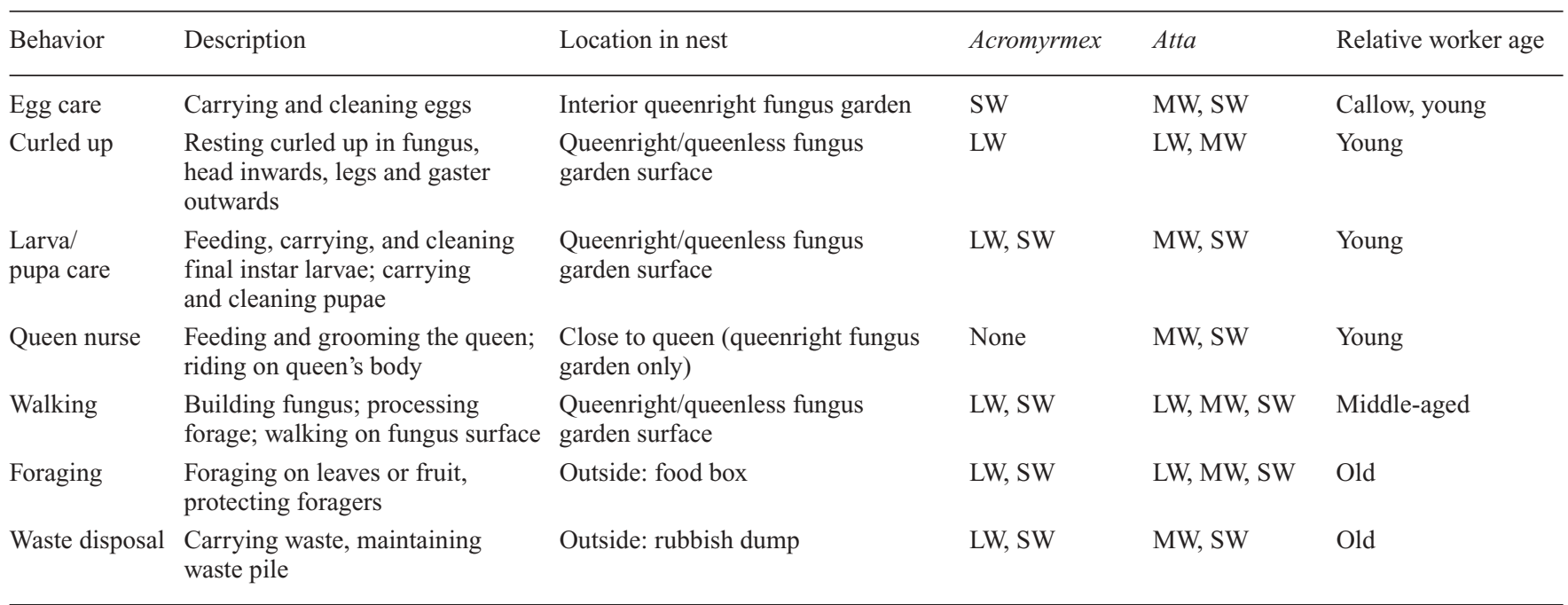

dorsal view, excluding the eyes. When sampling workers, we further distinguished seven categories, based on behavior and location in the nest (Table 2). In both genera, workers display an age-graded polyethism, with the oldest workers working outside the fungus gardens. Within each category, we sampled approximately 15 workers at random for each sub-caste. However, not all combinations of species, subcastes, and categories occur (Table 2). Sampling was done separately for the fungus garden in which the queen was located (hereafter the queenright fungus garden), and one fungus garden from which the queen was absent (hereafter the queenless fungus garden). Workers were able to move freely between fungus gardens. Two behavioral categories (egg care and queen nursing) only occur in queenright fungus gardens. We collected workers from the fungus gardens with forceps and immobilized them on ice. Workers were killed and dissected immediately, or stored at $-20{ }^{\circ} \mathrm{C}$ for later dissection. Comparisons showed that freezing had no effect on the oocytes except to fix the fluid yolk of medium-sized yolky oocytes in arbitrary shapes. We dissected workers by gently pulling the last gastral sternite loose with Dumont INOX\#5 forceps, while holding the worker submerged in insect saline solution (ISS; $7.5 \mathrm{~g}$ $\mathrm{NaCl}, 0.35 \mathrm{~g} \mathrm{KCl}, 0.278 \mathrm{~g} \mathrm{CaCl}_{2} \cdot 2 \mathrm{H}_{2} \mathrm{O}$, in $1 \mathrm{~L}$ double-distilled water). The ovaries were mounted on a microscope slide with a droplet of ISS and examined at $40 \times$ or $57 \times$ magnification under a stereomicroscope. Selected ovaries were also examined in distilled water at $1000 \times$ magnification with oil immersion under a dark-field compound microscope. For each ovariole, we noted the number of oocytes containing yolk, the degree of resorption of the internal ovariole structure, and the presence or absence of corpora lutea. For each oocyte containing yolk, we scored the length, maximum width, shape, and the presence or absence of a cluster of functional nurse cells. We also classified the color and degree of translucence of the oocyte: colorless and fully transparent (very young non-yolky oocyte); light yellow translucent (young growing oocyte); white translucent (non-fertile, middle-aged to mature oocyte: see figs. 1d-g); and white opaque (fertile, middle-aged to mature oocyte: see figs. 1c,i). Because yolk is opaque white in color, the degree of translucence gives an estimate of the yolk density inside the oocyte. For comparison with oocytes in workers, we also dissected small numbers of Acromyrmex mother queens, gynes, callow workers and orphaned workers (Fig. 1). Finally, we measured reproductive eggs from queenright fungus gardens of all four species.

Statistical analyses were performed using JMP v 5.01 for Macintosh (SAS Institute inc., 2002) with the exception of multinomial general linear models (GLMs) which were performed using GLMStat X 5.7.6 for Macintosh (Beath, 2004).

\section{Results}

\section{Worker head widths}

In Acromyrmex, worker head widths were $2.08 \pm 0.17 \mathrm{~mm}$ (Mean $\pm \mathrm{SD}, \mathrm{n}=364$ ) in Ac. echinatior LW, $1.25 \pm 0.24 \mathrm{~mm}$ $(\mathrm{n}=252)$ in Ac. echinatior SW, $2.33 \pm 0.29 \mathrm{~mm}(\mathrm{n}=271)$ in Ac. octospinosus LW, and $1.04 \pm 0.24 \mathrm{~mm}(\mathrm{n}=281)$ in Ac. octospinosus SW. In Atta, head widths were $4.46 \pm 0.74$ $\mathrm{mm}(\mathrm{n}=127)$ in At. cephalotes LW, $1.75 \pm 0.25 \mathrm{~mm}(\mathrm{n}=486)$ in At. cephalotes MW, $0.95 \pm 0.22 \mathrm{~mm}(\mathrm{n}=332)$ in At. cephalotes SW, $3.56 \pm 0.42 \mathrm{~mm}(\mathrm{n}=200)$ in At. sexdens LW, $1.89 \pm 0.33 \mathrm{~mm}(\mathrm{n}=415)$ in At. sexdens $\mathrm{MW}$, and $0.87 \pm$ $0.20 \mathrm{~mm}(\mathrm{n}=397)$ in At. sexdens SW.

\section{General morphology of the leafcutter worker reproductive apparatus}

Females of leafcutter ants have a pair of telotrophic ovaries with one to several hundred ovarioles per ovary. In telotrophic ovaries, clusters of nurse cells alternate with developing oocytes, with each oocyte lying proximal to its nurse cell cluster. Typical of Hymenopteran telotrophic ovaries is that each nurse cell cluster lies in its own follicle separate from the follicle around the oocyte. In oocytes that accumulate yolk, a bridge of cytoplasm connects the oocyte with the nurse cells via a gap in the follicles. The nurse cells later eject their cytoplasm into the oocyte and degenerate, leaving an empty follicle distal to the oocyte follicle. When an o ocyte is ovulated, the ruptured oocyte follicle (corpus luteum) with the empty nurse cell follicle remains, connected to the next oocyte follicle by a ligament of pre-follicular cells (Fig. 1d; see also Minkenberg and Petit, 1985). The corpus luteum then degenerates, may become dark yellow (Fig. 1i), and may be resorbed or extruded with the next laid egg. 

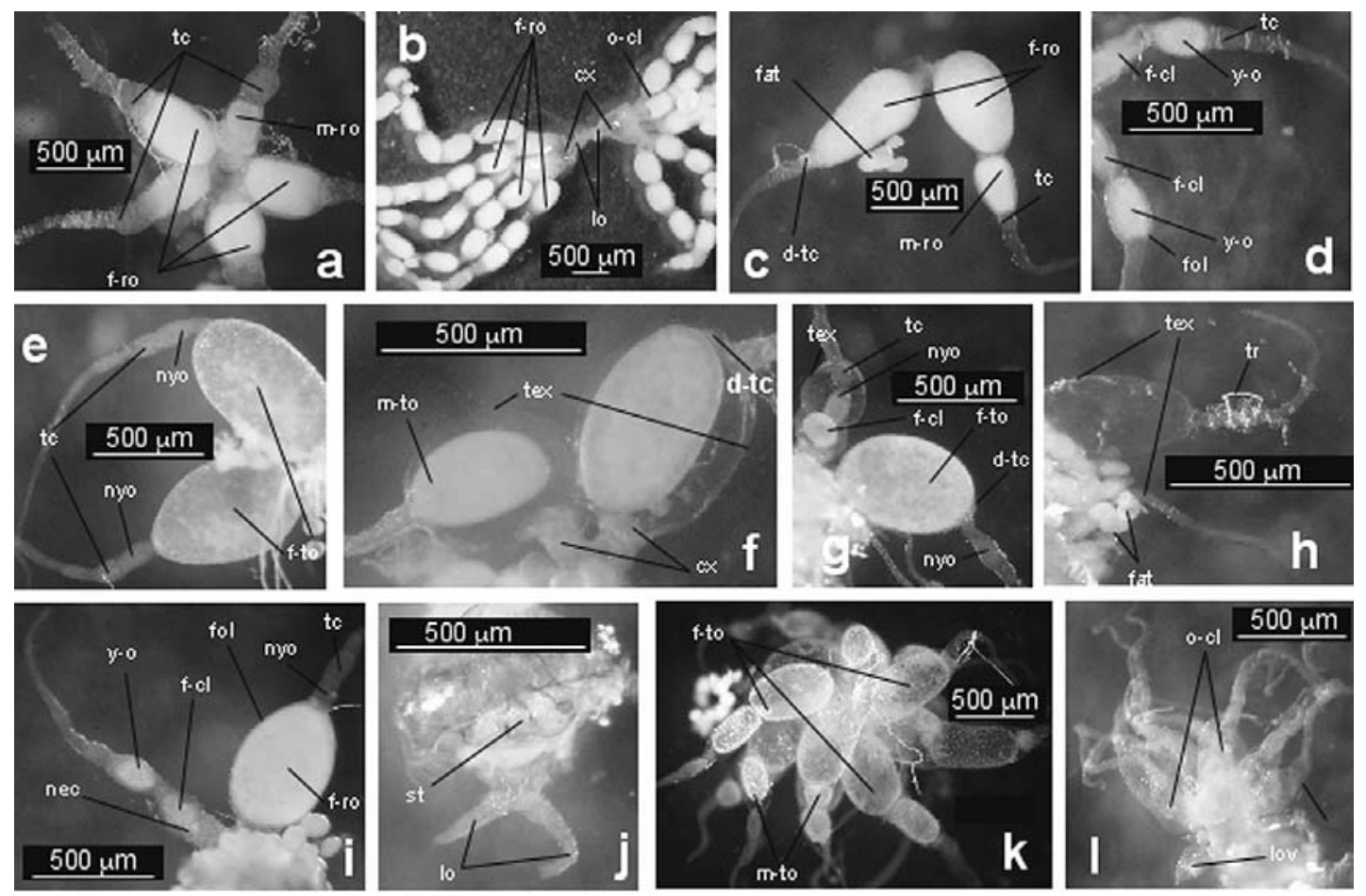

Figure 1. Ovaries of leafcutter ants. a: One ovary of an Ac. echinatior virgin queen; b: Ovaries of an Ac. echinatior established mother queen. Note the yellow-coloured debris from breakdown of corpora lutea in the calyxes; c: Ovaries of an orphaned Ac. octospinosus worker with three reproductive eggs in various stages of development; d: Ovaries of a queenright Ac. octospinosus worker that recently laid an egg from each ovariole, as evident from the fresh corpora lutea (ruptured follicles); e: Ovaries of a queenright Ac. echinatior worker with two ready-to-lay trophic eggs; f: Ovaries of a queenright Ac. octospinosus worker with a ready-to-lay trophic egg in the right ovary and a medium-sized trophic egg in the left ovary. Both ovaries are in the first stage of ovary resorption, with the tunica externa separating from the vitellarium and billowing outwards; g: Ovaries of a queenright Ac. echinatior worker, with a ready-to-lay trophic egg in the right ovary and a fresh corpus luteum proximal to a non-yolky oocyte in the left ovary. The left ovary is in an advanced state of ovary regression; h: Completely resorbed ovaries of a queenright Ac. echinatior worker; i: Ovaries of a queenright reproductive Ac. echinatior worker. Note the opaque egg (presumed to be viable) in the right ovary. Part of the corpus luteum in the left ovary is becoming yellow, indicating the onset of corpus luteum breakdown; j: Rudimentary ovaries typical of most queenright Atta workers. No ovarioles have yet grown from the lateral oviducts, and the common oviduct and lateral oviducts lack a lumen; k: Trophic ovary of a queenright At. sexdens media worker from the queen retinue with 14 ovarioles per ovary. The other ovary is rudimentary and invisible. 1: Degenerated left ovary (right ovary in picture) of a queenright At. cephalotes worker that formerly laid trophic eggs. The internal ovariole structure has been resorbed, leaving yellow-coloured degraded corpora lutea lying loose inside the ovarioles. The rudimentary right ovary is visible in the lower left corner. cx: calyx; d-tc: degenerated trophocyte cluster; fat: fat cell; f-cl: fresh corpus luteum; fol: follicle: f-ro: full-sized reproductive oocyte; f-to: full-sized trophic oocyte; lo: lateral oviduct; loy: left ovary; m-ro: medium-sized reproductive oocyte; m-to; medium-sized trophic oocyte; nec: necrotic corpus luteum cells: nyo: nonyolky oocyte; o-cl: old (degenerated) corpus luteum; st: sting; tc: trophocyte cluster; tex: tunica externa; tr: tracheoles; y-o: young yolky oocyte.

In all these aspects, leafcutter ants are typical of Hymenopteran females.

Acromyrmex and Atta worker ovaries differ in several respects. First, Acromyrmex workers eclose with fully formed ovarioles and reproductive tracts, although the ovarioles do not yet contain visible oocytes. In contrast, Atta workers have only rudimentary ovaries and reproductive tracts at eclosion (Fig. 1j). In young Atta workers, the lateral oviducts, common oviduct, and uterus lack a lumen, and the ovarioles are absent. In older Atta workers, the reproductive tract may develop and ovarioles may grow from the distal end of the lateral oviducts. However, in most Atta workers the ovaries and reproductive tract appear to develop only slightly and never become functional. Second, ovary size and the stage of development of the oocytes were similar in the left and right ovary of all dissected Acromyrmex workers. In ovary-developed Atta workers, either the right or left ovary was developed and contained oocytes, while the other ovary was completely undeveloped (Figs. 1k, 1). Third, laying Atta workers are more productive than laying Acromyrmex workers. Most Ac. echinatior and Ac. octospinosus workers had only a single ovariole per ovary, irrespective of worker size, although a single Ac. echinatior LW had two ovarioles in one ovary. In contrast, At. sexdens and At. cephalotes laying workers had 1-16 and 1-9 functional ovarioles per ovary, respectively. For comparison, queens of Ac. echinatior and Ac. octospinosus have 5-6 ovarioles per ovary (M.B. Dijkstra, personal observation), while Atta queens may have over 300 ovarioles per ovary (Tschinkel, 1987).

In laying Atta workers, the number of functional ovarioles increased significantly with increasing head width (Fig. 2; double log-transformed linear regression: At. sexdens: slope $=1.23, \mathrm{r}^{2}=0.62, \mathrm{p}<0.0001 ;$ At . cephalotes: slope $=0.98, \mathrm{r}^{2}$ $=0.32, \mathrm{p}<0.0001)$. This means that large Atta workers can 

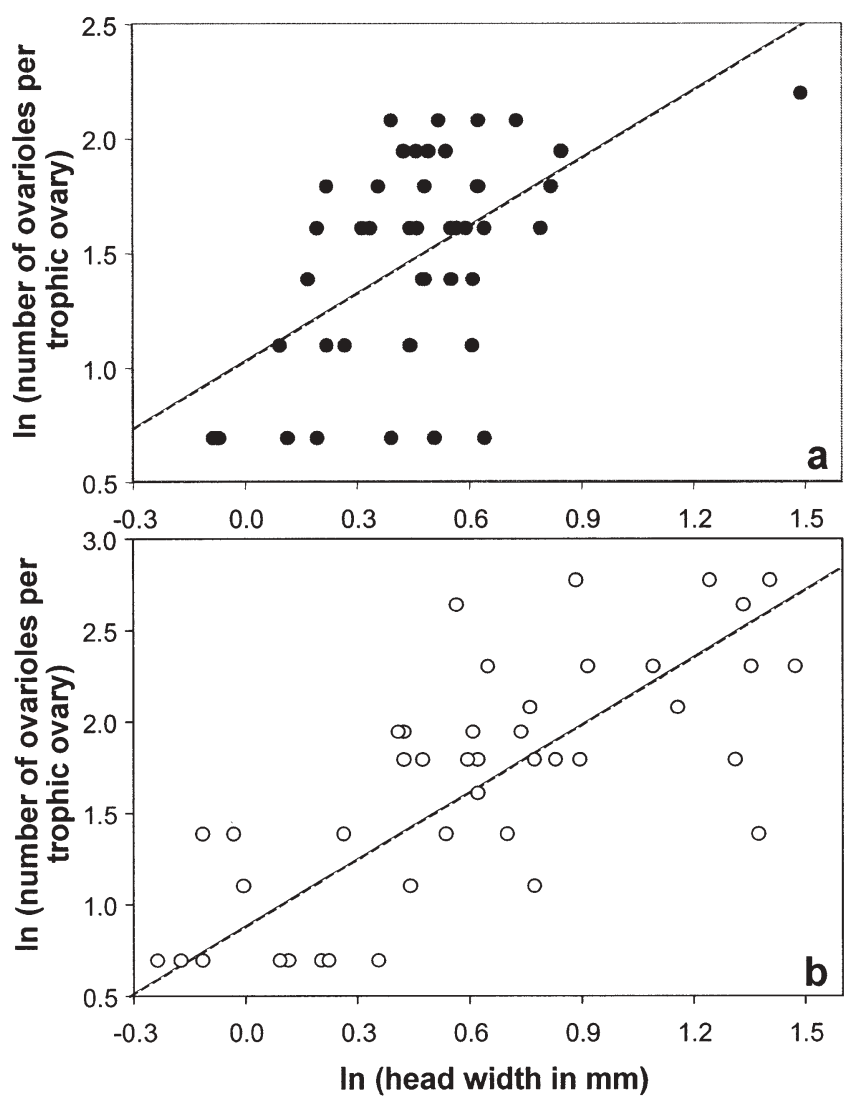

Figure 2. The number of ovarioles per developed ovary increases with head width in (a) Atta cephalotes and (b) Atta sexdens workers that have a trophic ovary. Both axes have been natural-log transformed.

potentially lay more eggs than small workers. In addition, none of the dissected queenright Acromyrmex workers had more than one mature egg per ovariole, while laying Atta workers frequently had 2-3 nearly complete oocytes per ovariole. The refractory period between ovulations from the same ovariole is thus likely to be shorter in Atta than in Acromyrmex. Fourth, the largest Atta workers (head width $>4 \mathrm{~mm}$ ) had non-functional spermathecae that are far smaller than those of virgin queens, while smaller Atta workers, and all dissected Acromyrmex workers, lacked spermathecae entirely.

\section{Comparing worker-produced eggs and eggs from fungus gardens}

Once laid, leafcutter ant reproductive eggs are sticky and lie in clumps in the interior of the queenright fungus garden. We assumed that all eggs obtained from the egg piles in the fungus garden were queen-derived, an assumption which has been validated in Ac. echinatior by genotyping of eggs (M.B. Dijkstra and J.J. Boomsma, unpublished data). In Acromyrmex, clumps of 5-40 young eggs are completely surrounded by an envelope of fungal hyphae, although older eggs may be solitary. In Atta, egg clumps contained hundreds
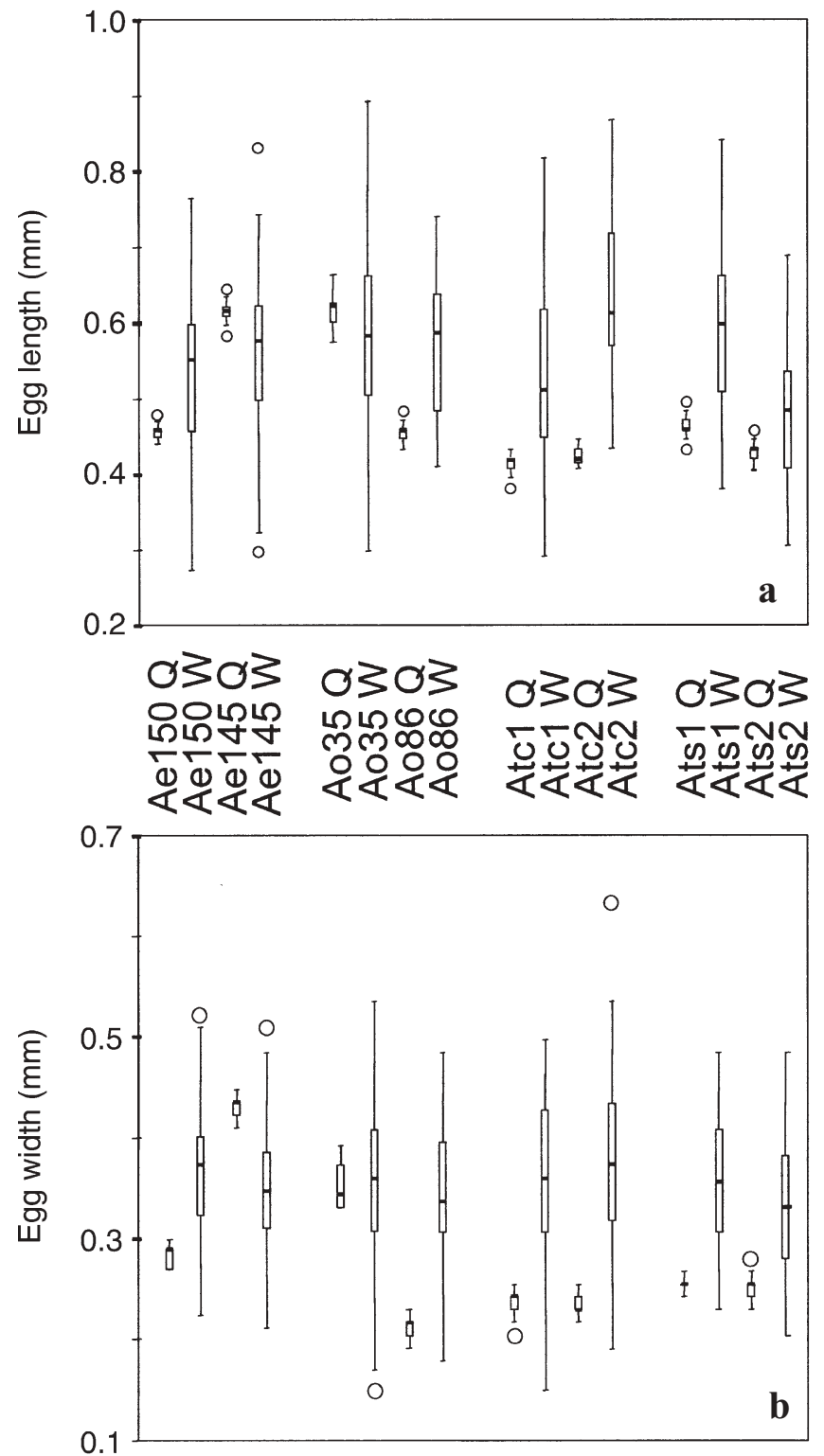

Figure 3. Box plots showing the length (a) and width (b) of eggs from fungus gardens (assumed to be exclusively queen-laid) and of ready-tolay eggs inside worker ovaries. Bold horizontal bars: median; box contours: $50 \%$ quartiles; error bar: $95 \%$ confidence intervals; open circles: outliers. Ae: Acromyrmex echinatior; Ao: Ac. octospinosus; Atc: Atta cephalotes; Ats: Atta sexdens.

of eggs, without a fungus envelope. Eggs from fungus gardens were similar in size within each colony, but highly variable between colonies of the same species (Fig. 3). This indicates that egg dimensions are idiosyncratic and specific for the queens that lay them. In all four species, workers produced ready-to-lay eggs (defined as regularly-shaped terminal oocytes with a fully collapsed nurse cell cluster) of similar size (Fig. 3). To compare the sizes of ready-to-lay worker eggs with queen-laid eggs from fungus gardens, we fitted a General Linear Model (GLM) with egg length as the dependent variable, and species, colony nested within species, and caste of the egg's mother (worker or queen) as explanatory 
variables. Separate analyses were performed for Atta and Acromyrmex. In Acromyrmex, only colony was highly significant ( $<<0.0001)$, while all other variables were non-significant (all $\mathrm{p}>0.3$ ). This means that egg length is highly variable between colonies, but worker- and queen-produced eggs have the same overall length distribution in either Acromyrmex species. In Atta, both caste and colony were highly significant predictor variables $(\mathrm{p}<0.0001)$. This means that Atta worker eggs are significantly larger than queen eggs, and that egg length varies significantly between colonies.

\section{Resorption of ovaries}

Older workers in all four species tend to resorb the ovariole internal structure, including the oocytes. In the first stage of this process, the ovariole tunica loosens from the vitellarium and billows outward (Fig. 1f). As the elasticity of the tunica is important in ovulation and movement of the follicles down the ovariole, this change implies sterility of the affected ovariole. Subsequently, the developing oocytes and attached corpora lutea are pulled back towards the distal ovariole and shrink (Fig. 1g). In the final stage of this process, only empty tunicae remain (Figs. 1h,l), of which the lumens occasionally contain dark yellow loose-lying corpora lutea. Ovariole resorption appears irreversible and can start irrespective of the developmental stage of the terminal oocytes. Ovariole resorption was not always synchronized between ovaries, or between ovarioles of the same ovary. Ovary resorption appears to be the ultimate fate of all Acromyrmex workers. In Atta workers, resorption was only observed in developed ovaries. In none of the studied species did we find evidence for resorption of individual oocytes, without parallel resorption of the entire ovariole.

\section{Laying Atta workers}

Atta workers with a developed ovary produced only large, flaccid eggs that were transparent when at full size due to lack of yolk (Fig. 1k), strongly suggesting that they are trophic and inviable. The eggs were irregularly shaped inside the ovarioles, but assumed a regular spherical shape when dissected out, demonstrating the flexibility of the chorions. The presence of corpora lutea attached proximal to the terminal follicles indicates that the produced eggs are laid. Workers with a trophic ovary were not equally distributed within the colonies (Fig. 4a, b, c). We analyzed their distribution by fitting a full factorial nominal logistic model using the presence or absence of a trophic ovary as the binary response variable, and the factors species, colony nested within species, subcaste, and behavior as explanatory variables. For greater statistical power and because some behaviors were only carried out by particular sub-castes, we collapsed the behaviors "egg care", "larval/pupal care", "walking", and "curled up" into "other activities", and collapsed "waste disposal" and "foraging" into "outside behaviors". The behavior "queen nurse" was retained as a separate category since this is shown only

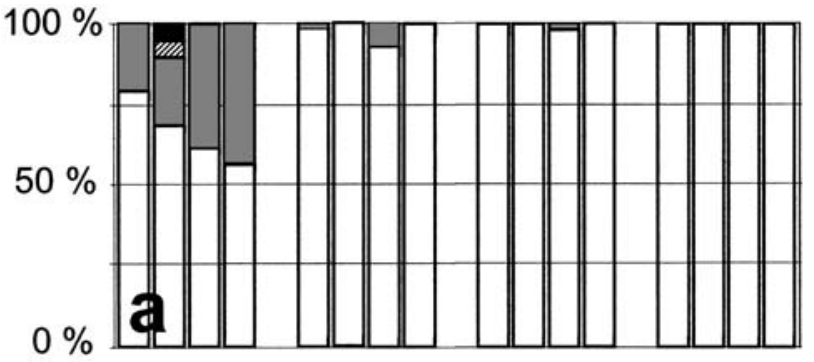

$100 \%$

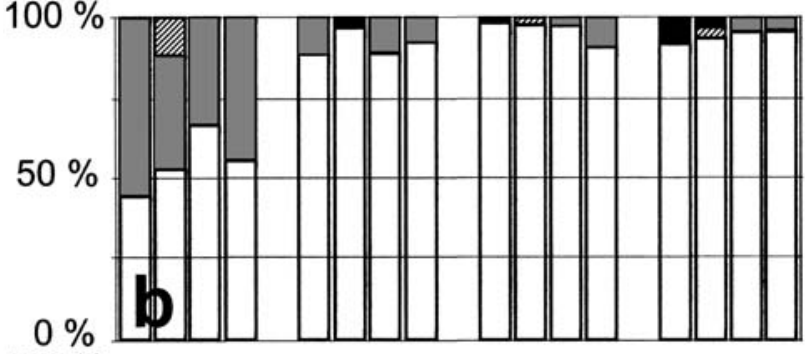

$100 \%$

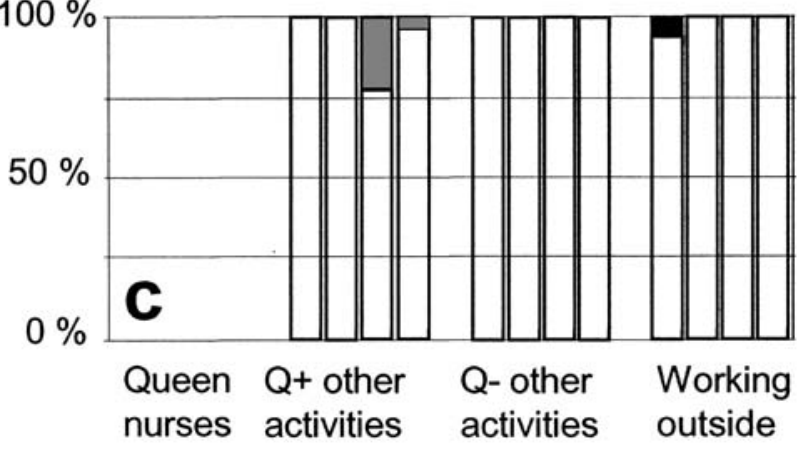

$\square$ One regressed ex-trophic ovary $\square$ One trophic ovary

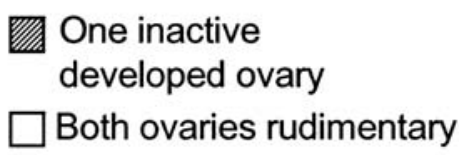

Figure 4. Types of ovaries found among small (a), media (b), and large (c) Atta workers performing different tasks. Left to right within each cluster of four bars: colonies AtcT1, AtcT2, Ats1, and Ats2.

in very close proximity to (usually on top of) the queen. However, since this behavior is only shown by SW and MW, we carried out two separate analyses. The first included all sub-castes but excluded the behavior "queen nurse". This showed a small and insignificant difference between colonies within each species $(p=0.0922)$, with none of the other explanatory variables significant (all $p>0.9$ ). This shows that there was no difference between species, colonies, subcastes, and behaviors (excluding queen nursing) in the probability of a worker having a trophic ovary. The full ANOVA table is given in Table 3a. In the second analysis, we included all behaviors, but excluded LW from the analysis. The full ANOVA table is given in Table $3 \mathrm{~b}$. The factor behavior was highly significant, indicating that queen nurses were significantly more likely to have a trophic ovary than workers in all other activities. All other explanatory variables and all interactions were non-significant $(p>0.1)$, indicating that the distribution of trophic egg layers did not differ between Atta colonies, nor between SW and MW. 
Table 3a. Results of nominal logistic analysis of the probability of Atto workers having trophic oocytes present or absent, including all subcastes but excluding the behavior "queen nurse".

\begin{tabular}{llll}
\hline Source & df & Wald $\chi^{2}$ & $\mathrm{P}$ \\
\hline Species & 1 & 0.0131 & 0.909 \\
Sub-caste & 2 & 0.00437 & 0.998 \\
Behavior & 1 & 0.00608 & 0.938 \\
Sub-caste $\times$ Species & 2 & 0.00178 & 0.999 \\
Behavior $\times$ Species & 1 & 0.0000734 & 0.993 \\
Behavior $\times$ Sub-caste & 2 & 0.000961 & 0.999 \\
Species $\times$ Sub-caste $\times$ Behavior & 2 & 0.00346 & 0.998 \\
Colony within Species & 2 & 4.77 & 0.0922
\end{tabular}

Table 3b. Results of nominal logistic analysis of the probability of Atta workers having trophic oocytes present or absent, including all behaviors but excluding the sub-caste "large workers".

\begin{tabular}{lllr}
\hline Source & df & Wald $\chi^{2}$ & \multicolumn{1}{c}{$\mathrm{P}$} \\
\hline Species & 1 & 0.0168 & 0.897 \\
Sub-caste & 1 & 0.0175 & 0.895 \\
Behavior & 2 & 80.6 & $<\mathbf{0 . 0 0 0 1}$ \\
Sub-caste $\times$ Species & 1 & 0.00524 & 0.942 \\
Behavior $\times$ Species & 2 & 2.09 & 0.351 \\
Behavior $\times$ Sub-caste & 2 & 1.73 & 0.421 \\
Species $\times$ Sub-caste $\times$ Behavior & 2 & 0.291 & 0.865 \\
Colony within Species & 2 & 3.90 & 0.142 \\
& & &
\end{tabular}

\section{Laying Acromyrmex workers}

Overall, $25 \%$ of Ac. octospinosus SW, $54 \%$ of $A c$. octospinosus $\mathrm{LW}, 52 \%$ of Ac. echinatior $\mathrm{SW}$, and $69 \%$ of $A c$. echinatior LW produced large, spherical, inflexible eggs with apparently normal chorions. Over $60 \%$ of ovarioles with yolky oocytes contained corpora lutea attached proximal to the terminal follicle, showing that Acromyrmex workers frequently lay the eggs that they produce. The oocytes in their ovaries varied greatly in opaqueness, apparently due to a continuous variation in yolk density inside the oocytes. A total of five $(0.8 \%)$ dissected Ac. echinatior workers, including LW and SW from both Ac. echinatior colonies, had ready-to-lay eggs that were completely opaque and indistinguishable from those produced by queens and orphaned workers (cf. Fig. 1i). We infer that only these eggs are viable. No completely opaque ready-to-lay eggs were found in Ac. octospinosus workers. However, the difference between the two Acromyrmex species in the proportions of viable-looking oocytes did not quite reach significance (Fisher exact test, $p$ $=0.0641)$. Most workers in both Acromyrmex species produced eggs that were translucent to varying degrees, indicating that they contain less yolk than eggs of gynes, mother queens, and orphaned workers. We assumed all translucent eggs to be inviable or to have reduced viability. We were unable to assign the youngest yolky oocytes to the viable or inviable category.

Workers with yolky oocytes in their ovaries were not equally distributed within the colonies (Fig. 5a,b). We analyzed their distribution by fitting a full factorial nominal
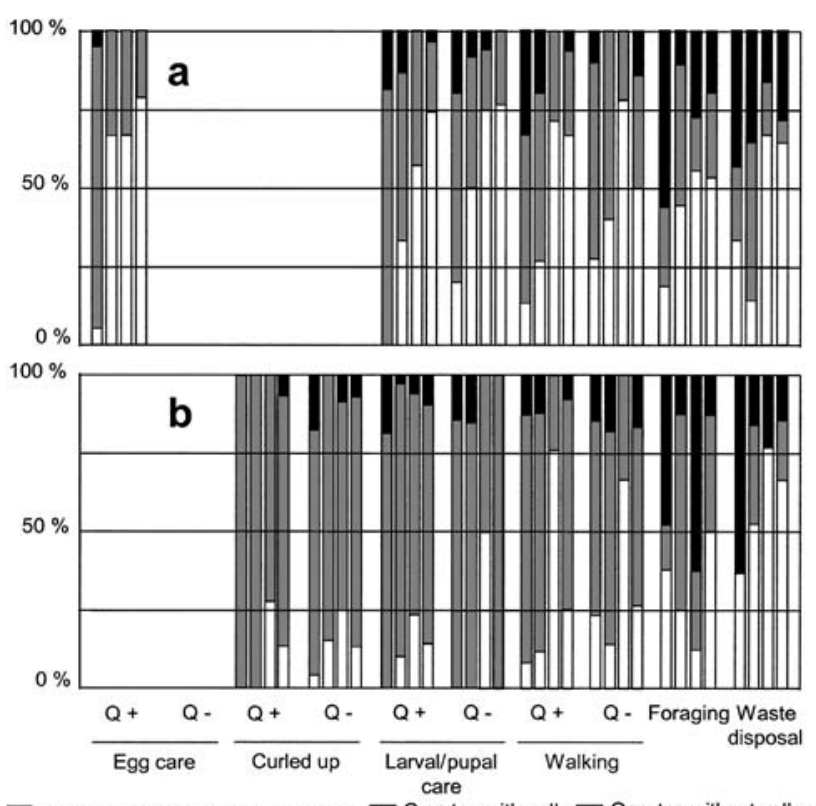

Fully or partially resorbed ovarioles $\square$ Oocytes with yolk $\square$ Oocytes without yolk only

Figure 5. Types of ovaries found among small (a) and large (b) Acromyrmex workers performing different tasks. Left to right within each cluster of four bars: colonies Ae150, Ae145, Ao86, and Ao35.

logistic model using the presence or absence of yolky eggs as the binary response variable, and the factors species, colony nested within species, sub-caste, presence or absence of the queen in the same fungus garden as the worker, and worker behavior as explanatory variables. Since some behaviors are sub-caste or location specific (Fig. 5), only ants engaged in activities in or on the fungus garden were included in the analysis, and "curled up" ants were excluded (since this behavior is only shown by LW). This analysis showed a significant difference between species, with Ac. echinatior being more likely than $A c$. octospinosus to have yolky eggs present. There were also significant effects of sub-caste, behavior and their interaction, with LW being much more likely to have yolky eggs present than SW, ants caring for eggs or brood being more likely to have yolky eggs than those walking on the fungus garden, and with SW walking on the fungus garden having a further reduced probability of having developed yolky eggs. The full ANOVA table for the analysis is given in Table 4a. Since only LW were found curled up in the fungus garden, the probability of their having developed ovaries was compared with that of the other LW workers confined to the fungus garden (i.e., those tending brood or eggs), also using a full factorial nominal logistic analysis. This showed that there was no significant difference between LW curled up and those tending eggs or brood in their probability of having developed yolky oocytes (Wald $\chi^{2}<0.06, p>0.8$ for all main effects and interactions, Wald $\chi^{2}=1.98, \mathrm{p}=$ 0.373 for colonies nested within species).

Within the fungus garden, most Acromyrmex workers have a low probability of showing signs of resorbed ovarioles, while those engaged in foraging or waste disposal outside the fungus garden appear to have a greater probability of 
Table 4a. Results of nominal logistic analysis of the probability of Acromyrmex workers having yolky oocytes present or absent, excluding the behavior "curled up" (only shown by large workers) and all workers found outside the fungus gardens.

\begin{tabular}{lllr}
\hline Source & df & Wald $\chi^{2}$ & \multicolumn{1}{c}{$\mathrm{P}$} \\
\hline Species & 1 & 22.1 & $<\mathbf{0 . 0 0 0 1}$ \\
Queen (presence or absence) & 1 & 0.103 & 0.748 \\
Sub-caste & 1 & 43.2 & $<\mathbf{0 . 0 0 0 1}$ \\
Behavior & 1 & 6.62 & $\mathbf{0 . 0 1 0}$ \\
Species $\times$ Queen & 1 & 0.920 & 0.338 \\
Species $\times$ Sub-caste & 1 & 2.87 & 0.0900 \\
Queen $\times$ Sub-caste & 1 & 0.124 & 0.725 \\
Species $\times$ Behavior & 1 & 0.148 & 0.701 \\
Queen $\times$ Behavior & 1 & 0.0000236 & 0.996 \\
Sub-caste $\times$ Behavior & 1 & 7.92 & $\mathbf{0 . 0 0 4 9}$ \\
Species $\times$ Queen $\times$ Sub-caste & 1 & 0.919 & 0.338 \\
Species $\times$ Queen $\times$ Behavior & 1 & 0.156 & 0.693 \\
Species $\times$ Sub-caste $\times$ Behavior & 1 & 0.845 & 0.358 \\
Queen $\times$ Sub-caste $\times$ Behavior & 1 & 2.77 & 0.0963 \\
Species $\times$ Queen $\times$ Sub-caste & & & \\
$\quad \times$ Behavior & 1 & 0.0144 & 0.904 \\
Colony within Species & 2 & 5.90 & 0.0522 \\
\hline
\end{tabular}

Table $4 \mathbf{b}$. Results of fitting a multinomial logit model of the probability of Acromyrmex workers having oocytes falling into each of the three categories "non-yolky oocytes", "yolky oocytes" and "resorbed oocytes".

\begin{tabular}{lccr}
\hline Source & df & $\begin{array}{l}\Delta \text { scaled } \\
\text { deviance }\end{array}$ & $\mathrm{p}$ \\
\hline Species & 2 & 18.56 & $<\mathbf{0 . 0 0 0 1}$ \\
$\begin{array}{l}\text { Location (within or outside } \\
\quad \text { fungus garden) }\end{array}$ & 2 & 18.13 & $\mathbf{0 . 0 0 0 1}$ \\
Sub-caste & 2 & 12.94 & $\mathbf{0 . 0 0 1 6}$ \\
Species $\times$ Location & 2 & 0.259 & 0.879 \\
Species $\times$ Sub-caste & 2 & 2.13 & 0.347 \\
Location $\times$ Sub-caste & 2 & 3.11 & 0.211 \\
Species $\times$ Location $\times$ Sub-caste & 2 & 0.919 & 0.338 \\
Colony replacing Species & 6 & 7.17 & 0,305 \\
\hline
\end{tabular}

resorbing ovarioles (Fig. 5). Since oocytes could fall into three categories (with yolk, without yolk, resorbed), the significance of this difference was tested using a GLM with multinomial logit error structure (Crawley, 1993). The dependent variable was the number of workers with oocytes in each of the three categories. Main effects were location of the worker (within or outside the fungus garden), species, and sub-caste. All interactions between main effects were also examined. After correction for over-dispersion in the data (Crawley, 1993), analysis was performed by fitting of the full model, followed by model simplification to yield the minimal adequate model. The significance of the removal of each term was assessed by comparing the associated change in scaled deviance and degrees of freedom with the chisquared distribution. All the main effects, but none of the interactions, were retained in the minimal adequate model, showing that the proportion of workers with eggs in each of the three categories differed significantly between species (Ac. echinatior workers had more yolky oocytes and resorbed ovaries, and fewer non-yolky oocytes, than Ac. octospinosus workers), between sub-castes (LW had more yolky oocytes and resorbed ovaries, and fewer non-yolky oocytes, than SW) and depending on whether the worker was found inside or outside the fungus garden (interior workers had more yolky oocytes, and fewer non-yolky oocytes and resorbed ovaries than exterior workers). The effect of colony could not be examined directly by nesting it within species in such a mod$\mathrm{el}$, so instead its significance was estimated by examining the change in scaled deviance caused by substituting colony for species in the minimum adequate model. This showed no significant difference between colonies in the proportion of workers with oocytes in the three different states that could not be explained by species differences. The full analysis is presented in table $4 \mathrm{~b}$.

We compared the length of yolky oocytes, irrespective of level of development, that were present in LW and SW. We fitted a GLM with oocyte length as a dependent variable, and species, colony nested within species, and sub-caste as explanatory variables. Only sub-caste was significant ( $\mathrm{p}<$ $0.0001)$, while all other factors and interactions were nonsignificant $(\mathrm{p}>0.5)$. This means that worker oocyte length does not differ between Acromyrmex species, but LW have significantly longer oocytes than SW. Thus, LW are not only more likely to have yolky oocytes than SW, but yolky oocytes are also on average larger in LW compared to SW.

\section{Discussion}

\section{The loss of worker reproduction in attine ants}

Our results show that most queenright workers in all four species studied do not lay reproductive eggs. We found no viable-looking eggs inside workers of Ac. octospinosus, At. cephalotes, and At. sexdens. Our results are thus consistent with the absence of worker sons among genotyped males from queenright Ac. octospinosus colonies (Boomsma et al., 1999) and we predict that worker sons will likewise be absent in queenright colonies of At. sexdens and At. cephalotes. In contrast, very low numbers of worker sons may occur in queenright colonies of Ac. echinatior.

Acromyrmex workers, which can reproduce in orphaned colonies, show self-restraint in queenright colonies. Because Acromyrmex colonies may have thousands of workers and multiple fungus gardens, queens are unlikely to have the opportunity for queen policing. The observed reproductive self-restraint in Acromyrmex workers could be maintained by worker policing towards eggs or reproductive workers, provided that this worker policing is as effective as in honeybees (Ratnieks, 1988). Alternatively, worker self-restraint may be maintained by efficiency constraints related to worker morphology or worker-brood development time, which have recently been suggested to outweigh the relatedness advantage of worker sons versus queen sons in bumblebees (Duchateau et al., 2004). Detailed further laboratory studies will be needed to clarify which of these mechanisms apply in Acromyrmex leafcutter ants. 
In contrast to Acromyrmex, Atta workers appear to be completely incapable of reproduction. Except for the queen retinue, workers do not develop their ovaries beyond the rudimentary stage present in newly-eclosed workers, and never produce eggs. As Atta and Acromyrmex are sister genera (Wetterer et al., 1998), we hypothesize that the evolution of worker sterility in Atta may have started with worker selfrestraint as in Acromyrmex. Subsequently, larger colony size, increased queen-worker dimorphism, and a shorter life-span of orphaned colonies compared to Acromyrmex, combined with the costs of maintaining a reproductive apparatus in workers, may have made worker sterility adaptive in Atta. However, trophic functions of worker egg laying have been maintained in both genera of leafcutter ants, but in very different ways, so that we will focus the remaining part of the discussion on these aspects.

\section{The maintenance and elaboration of trophic functions of worker egg-laying}

A small subset of Atta workers, mostly SW and MW forming a retinue around the queen, lay many eggs in quick succession that are larger, more flaccid, and contain less yolk compared to queen-laid eggs. Bazire-Benazet (1957) observed that these eggs are fed to the queen. Physical contact with the queen may be the cue that induces Atta workers to develop trophic ovaries. The specialized morphology of the resulting eggs makes it highly unlikely that these eggs can ever develop. The occasional trophic egg layers that are found away from the queen may constitute a dynamic pool from which new queen nurses are recruited when needed. Alternatively, these workers may feed trophic eggs to the larvae. However, the rarity of trophic egg producing workers in queenless fungus gardens suggests that trophic eggs are not an important addition to the Atta larval diet. We found no evidence that Atta laying workers produce eggs through fusion of multiple oocytes, as reported by Bazire-Benazet (1957, 1970) for Atta queen nurses and founding queens. However, the trophic ovaries of At. sexdens and At. cephalotes workers look exactly as illustrated in BazireBenazet (1970). We frequently found multiple follicles containing large oocytes immediately adjacent to each other inside the ovariole, superficially suggesting fusion. However, these follicles were found to be separated by a ligament when the ovariole tunica was removed, without visible outgrowths of the oocytes into adjacent follicles. Also, contrary to the expectation if Atta worker eggs are produced through oocyte fusion, ready-to-lay eggs were not larger in workers of Atta than in Acromyrmex (Fig. 3). We thus remain unconvinced of the occurrence of oocyte fusion in Atta workers, although the phenomenon is well documented in founding queens (Bazire-Benazet 1957).

In Acromyrmex, many workers lay trophic eggs that contain less yolk than queen-laid Acromyrmex eggs, but more than Atta worker-laid eggs. In all studied aspects, Acromyrmex worker ovaries were similar to the ovaries of workers of Myrmica rubra, a non-fungus-growing myrmicine ant, as described by Minkenberg and Petit (1985). Indi- vidual Acromyrmex workers can lay only one egg per ovary at a time and must have a refractory period of several days between successive ovulations from the same ovary. Laying Acromyrmex workers appear to lay multiple eggs between eclosion and middle age. We never found trophic eggs lying among the brood, suggesting that they are fed directly to the larvae. The high frequencies of workers producing eggs among Acromyrmex workers caring for the larvae and pupae strongly suggest that their eggs are fed to the larvae, and possibly to the queen. Trophic worker-laid eggs may thus be an important part of the Acromyrmex larval diet, in addition to the fungal hyphae and gongylidia that are the staple larval food of all attine ants.

In Acromyrmex, large workers contain mature trophic eggs far more frequently than small workers, indicating that large workers are the main source of trophic eggs. The equal development of Acromyrmex worker ovaries in queenright and queenless fungus gardens suggests that proximity to the queen does not affect worker ovary development. This agrees with our conclusion that Acromyrmex worker-laid eggs are mainly destined to be eaten by larvae, as larvae are found in all fungus gardens. More workers produce eggs in Ac. echinatior than in Ac. octospinosus, suggesting that trophic eggs are a more important part of the larval diet in Ac. echinatior than in Ac. octospinosus. The higher frequency of trophic eggs inside worker ovaries of Ac. echinatior than of $A c$. octospinosus is also found when small, non-reproducing colonies are used (M.B. Dijkstra, personal observation). Thus the production of sexuals by the study colonies of $A c$. echinatior, but not of Ac. octospinosus (See Table 1), cannot explain the observed pattern. Some $(0.8 \%)$ of the dissected Ac. echinatior workers, but no Ac. octospinosus workers, had a normal-looking egg inside one of their ovaries. However, we may have underestimated the frequency of reproductive workers in Acromyrmex colonies, if intermediate-type eggs can also occasionally develop. Genotyping of developing eggs is necessary to solve this question. As Acromyrmex trophic and reproductive eggs appear to have similar morphologies apart from yolk density, individual Acromyrmex workers may shift to producing reproductive eggs in orphaned colonies by increased metabolism of the fat body and increased yolk uptake into the oocytes. Acromyrmex and Atta workers with ready-to-lay eggs that are kept in isolation do not spontaneously lay eggs, suggesting that workers can control ovulation and lay eggs only when needed. A larval- or queen-produced cue or signal may be necessary to induce ovulation in leafcutter ant workers.

In all four species studied, the older workers that work outside the fungus gardens tend to resorb their ovaries, which leaves them permanently unable to lay any eggs. Assuming that the main function of trophic eggs in Acromyrmex is larval feeding, the abortion of this function at a later age when nursing tasks are replaced by foraging tasks seems a logical development, because cessation of ovary maintenance may well enhance worker longevity or colony-level productivity at that stage. 


\section{Acknowledgements}

We thank Boris Baer and two anonymous referees for helpful comments on this study, the Smithsonian Tropical Research Institute (STRI) and the Autoridad Nacional del Ambiente (ANAM) for collection and export permits in Panama, and Ulrich Mueller for supplying the At. cephalotes colonies. This study was funded by a Ph.D. fellowship from the University of Copenhagen.

\section{References}

Bazire-Benazet, M., 1957. Sur la formation de l'oeuf alimentaire chez Atta sexdens rubropilosa, Forel, 1908 (Hym. Formicidae). C. R. Acad. Sc. Paris. 244: 1277-1280.

Bazire-Benazet, M., 1970. La ponte des ouvrières d'Atta laevigata Fred. Smith 1858 (Hym. Form.). C. R.. Acad. Sc. Paris 270: 1614-1615.

Beath, K.J., 2004. GLMStat Version 5.7.6, Newcastle, Australia: Author.

Boomsma, J.J., E.J. Fjerdingstad, and J. Frydenberg, 1999. Multiple paternity, relatedness and genetic diversity in Acromyrmex leafcutter ants. Proc. R.. Soc. Lond. Ser. B 266: 249-254.

Bourke, A.F.G., 1988. Worker reproduction in the higher eusocial Hymenoptera. Quart. Rev. Biol. 63: 291-311.

Choe, J.C., 1988. Worker reproduction and social evolution in ants (Hymenoptera: Formicidae). In: Advances in Myrmecology (J.C. Trager, Ed.). E.J. Brill, New York. pp 163-87.

Cole, B.J., 1986. The social behavior of Leptothorax allardycei (Hymenoptera, Formicidae): time budgets and the evolution of worker reproduction. Behav. Ecol. Sociobiol. 18: 253-60.

Cole, B.J. and D.C. Wiernasz, 1999. The selective advantage of low relatedness: growth in the harvester ant, Pogonomyrmex occidentalis. Science 285: 491-493.

Crawley, M.J., 1993. GLIM for Ecologists. Blackwell Science, Oxford. $379 \mathrm{pp}$.

Crespi, B.J., 1992. Cannibalism and trophic eggs in subsocial and eusocial insects. In: Cannibalism. Ecology and Evolution among diverse taxa. (Elgar, M. A. and B.J. Crespi, Eds.). Oxford Science Publications. pp. 177-212.

Duchateau, M.J., H.H.W. Velthuis, and J.J. Boomsma, 2004. Sex ratio variation in the bumblebee Bombus terrestris. Behav. Ecol. 15: 71-82.

Fjerdingstad, E.J., J.J Boomsma, and P. Thorén, 1998. Multiple paternity in the leafcutter ant Atta colombica. Heredity 80: 118-126.

Fjerdingstad, E.J. and J.J. Boomsma, 2000. Queen mating frequency and relatedness in young Atta sexdens colonies. Insectes soc. 47: 354-356.

Foster, K.R., and F.L.W. Ratnieks, 2000. Facultative worker policing in a wasp. Nature 401: 692-693.
Foster, K.R., J. Gulliver, and F.L.W. Ratnieks, 2002. Worker policing in the European hornet Vespa crabro. Insectes soc. 49: 41-44.

Foster, K.R., and F.L.W. Ratnieks, 2001. The effect of sex-allocation biasing on the evolution of worker policing in Hymenopteran societies. Am. Nat. 158: 615-622.

Foster, K.R., and F.L.W. Ratnieks, 2001a. Convergent evolution of worker policing by egg eating in the honey bee and common wasp. Proc. R.. Soc. Lond. B 268: 169-171.

Hölldobbler, B. and E.O. Wilson, 1990. The Ants. Springer-Verlag, Berlin, Heidelberg. 732 pp.

Iwanishi, S., E. Hasegawa, and K. Ohkawara, 2003. Worker oviposition and policing behavior in the myrmicine ant Aphaenogaster smythiesi japonica Forel. Anim. Behav. 66: 513-519.

Kronauer, D.J.C., C. Schöning, J.S. Pedersen, J.J. Boomsma, and J. Gadau. Extreme queen-mating frequency and colony fission in African army ants. Mol. Ecol., in press.

Minkenberg, P.J.M. and M. Petit, 1985. Ovariole development in workers of Myrmica rubra linnaeus (Hymenoptera: Formicidae) and its relation to age-polyethism. Ann. Soc. R.. Zool. Belg. 115: 29-43.

Murakami, T., S. Higashi and D. Windsor, 2000. Mating frequency, colony size, polyethism and sex ratio in fungus-growing ants (Attini). Behav. Ecol. Sociobiol. 48: 276-284.

Ortius-Lechner, D., R. Maile, E.D. Morgan, H.C. Petersen, and J.J. Boomsma, 2003. Lack of patriline-specific differences in chemical composition of the metapleural gland secretion in Acromyrmex octospinosus. Insectes soc. 50:113-119.

Price, S.L., T. Murakami, U.G. Mueller, T.R. Schultz, and C.R. Currie, 2003. Recent findings in fungus-growing ants: evolution, ecology, and behavior of a complex microbial symbiosis. In: Genes, Behaviors and Evolution of Social Insects. (T. Kikuchi, N. Azuma and S. Higashi, Eds.) Hokkaido University Press, Sapporo. pp. 255-280.

Ratnieks, F.L.W., 1988. Reproductive harmony via mutual policing by workers in eusocial Hymenoptera. Am. Nat. 132: 217-36.

Ratnieks, F.L.W., and P.K. Visscher, 1989. Worker policing in the honeybee. Nature 342: 797-798.

SAS Institute inc., 2002. JMP version 5.0.1. SAS, Cary, NC.

Sumner, S., W.O.H. Hughes, J.S. Pedersen, and J.J. Boomsma, 2004. Ant parasite queens abandon multiple mating. Nature 428: 35-36.

Tschinkel, W.R., 1987. Relationship between ovariole number and spermathecal sperm count in ant queens: a new allometry. Ann. Entomol. Soc. Am. 80: 208-211.

Villesen, P. and J.J. Boomsma, 2003. Patterns of male parentage in the fungus-growing ants. Behav. Ecol. Sociobiol. 53: 246-253.

Wetterer, J.K., Schultz, T.R. and Meier, R. 1998. Phylogeny of the fungus-growing ants (Tribe Attini) based on mtDNA sequence and morphology. Mol. Phyl. Evol. 9: 42-47.

Wetterer, J.K., 1999. The ecology and evolution of worker-size distribution in leaf-cutting ants (Hymenoptera: Formicidae). Sociobiology 34: 119-144. 